\title{
The Role of Environment in the Socio-Cultural Changes of the Ancient Silk Road Area
}

\author{
Liang Emlyn Yang' ${ }^{1}$, J. Wiesehöfer ${ }^{2}$, H.-R. Bork ${ }^{3}$ and M. Hoo ${ }^{1,2}$ \\ Kiel, Germany, 28-29 September 2017
}

The Silk Road is a modern concept for an ancient network of trade routes that for centuries facilitated and intensified processes of cultural interaction and goods exchange between West China, Central Asia, the Middle East, and the Mediterranean (Elisseeff 2001). The Silk Road flourished when the Han dynasty explored Central Asia around $139 \mathrm{BCE}$ and thrived throughout the Middle Ages and eventually declined under the Islamic and Mongol Empires. There is increasing discussion that climatic and environmental factors may have played a role in fostering economic and socio-cultural changes along the Silk Road and in a broader area (Zhang et al. 2011). Coherent patterns and synchronous events in history suggest possible links between social upheaval, resource utilization, and climate or environment forces (Clarke et al. 2016; Mischke et al. 2017). Such links between climatic, environmental, economic, social, and cultural changes would have manifested themselves differently according to place and time; however, it often remains unclear if and how exactly they affected socio-cultural situations on the ground.

The international workshop "The Rise and Fall: Environmental Factors in the SocioCultural Changes of the Ancient Silk Road Area" was held at Kiel University. The Silk Road served as the geographical scope and inspirational concept for the workshop. Nineteen researchers from 12 countries presented topics on the expansion of Ancient China to the west; Central Asia as the key node area of the Silk Road; historical water and agriculture systems; climate and environment disasters in the past; climate links to social evolution; and changes of lake and sea regions from ancient to recent periods. The presentations investigated both perspectives of socio-environmental interactions; it became clear, for instance, that climate change provided better hydrological resources for the golden era of Silk Road trade, and that water withdrawn for human activities resulted in dramatic landscape changes including the near and complete desiccation of large lakes in the arid western part of today's China (Fig. 1). These topics were approached from various disciplinary angles and perspectives, ranging from archaeology, climate change, antiquity, historical geography, agriculture, carving art and literacy. Contributions focused on the middle to late Holocene and covered specific areas along the ancient Silk Road regions.

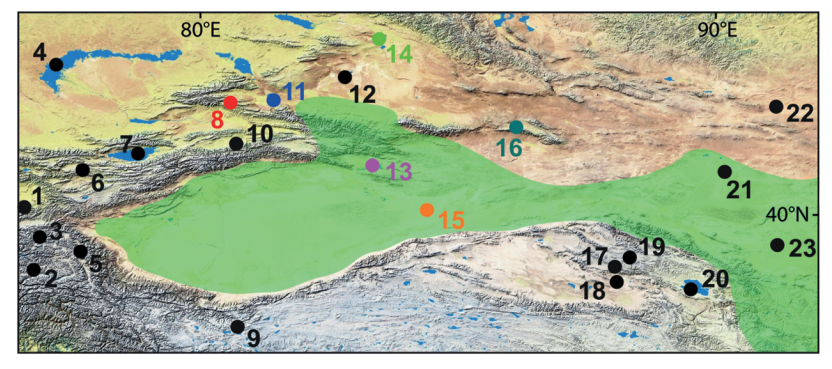

1 Uluu-Too 13 Bosten 2 Sasikul 14 Wulungu 3 Karakul 15 Lop Nur 4 Balkhash 16 Balikun 5 Karakuli 17 Dunde $\begin{array}{ll}5 \text { Karakuli } 17 \text { Dunde } \\ 6 \text { Son Kol } & 18 \text { Hurleg }\end{array}$ 7 Issyk-Kul 19 Hala 8 Sayram 20 Qinghai 9 Guliya 21 Eastern Juyan 10 Kesang 22 Ulaan 11 Aibi 23 Zhuyeze

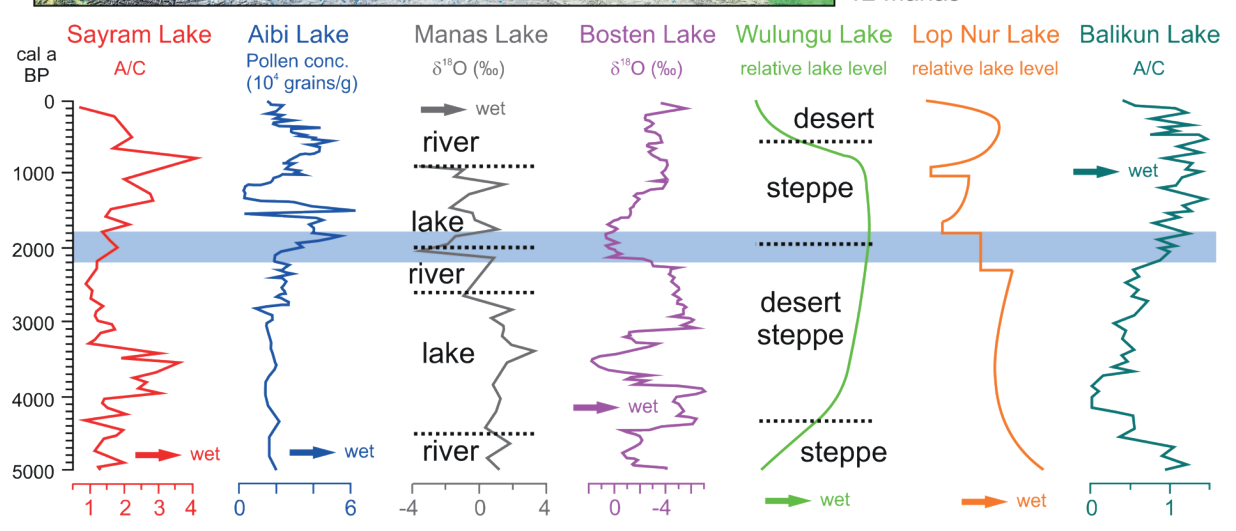

Figure 1: Proxy-and literature-based climate records suggesting massive human-induced landscape changes. The selected curves below the map illustrate wet conditions in specific regions. The green area on the map represents the extent of the Han Dynasty in today's Western China and the blue bar in the graphs refer to its period of occurrence (206 BCE - 220 CE). The Han dynasty is considered as the "golden age" of Chinese history and helped establish the Silk Road. A/C refers to the Artemisia to Chenopodiaceae pollen ratio which is used to differentiate between desert and steppe vegetation. Provided by Steffen Mischke and edited by Liang E. Yang.

The workshop also held a lunch seminar, which discussed joint publication and potential research cooperation. A proceeding book volume, with a proposed title "Socio-Environmental Dynamics along the Historical Silk Road", will be published by Springer. Eighteen full papers from participants have been received for peer review. To share information and to provide an opportunity to those interested in the topic but unable to attend the workshop, additional papers are invited from research groups and experts in the field.

The workshop increased our understanding of the role played by the environment in socio-cultural changes that occurred in the territories along the ancient Silk Roads, and initiated a network of both young and senior researchers to facilitate international connectivity and multidisciplinary cooperation. Moreover, participants expressed great interest in organizing a follow-up meeting and proposed ideas for cooperation in the near future, for instance, nomadic responses to water conditions at the front regions of the Tianshan Mountain.

\section{ACKNOWLEDGEMENTS}

The workshop was jointly supported by the Graduate School Human Development in Landscapes at the Kiel University and PAGES

\section{AFFILIATIONS}

Graduate School Human Development in Landscapes Kiel University, Germany

${ }^{2}$ Institute of Classical Antiquity, Kiel University,

Germany

${ }^{3}$ Institute for Ecosystem Research, Kiel University, Germany

\section{CONTACT}

Liang Emlyn Yang: lyang@gshdl.uni-kiel.de REFERENCES

Clarke J et al. (2016) Quat Sci Rev 136: 96-121 Elisseeff V (2001) The Silk Roads: Highways of Culture and Commerce. Berghahn Books, 352 pp

Mischke S et al. (2017) Sci Rep 7: 43102

Zhang DD et al. (2011) PNAS 108: 17296-17301 